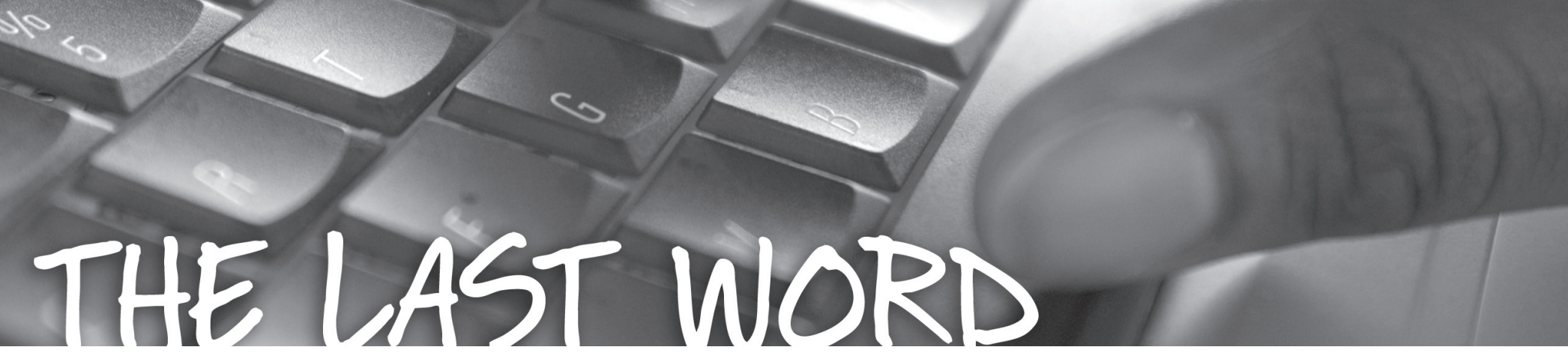

\title{
Putting the ROAR in Reading
}

\author{
Edwina Walker Amorosa
}

I want to enthusiastically ROAR and share a success story I have had with two of my grandchildren. Meet avid readers Nella, age nine, and Sameena, almost nine.

When Nella moved to Texas last summer and was concerned about losing contact, I suggested we form a book club. Along with Sameena, we dubbed it ROAR, for Rockin' Outrageous Awesome Reading! From the first word to the last, we experienced the joy of reading together via Skype, FaceTime, and conference calls. Here is a quick look at our book club.

A great name. It was derived from the Judy Moody series, where Judy shouts "Roar" whenever something great happens. Nella and Sam jubilantly created the acronym. Book discussions begin and end with a ROAR!

A cool uniform. We designed visors, with "ROAR" embroidered on them, to wear at our book discussions.

A note-taking system. I initially provided questions, and soon the girls began to formulate open-ended questions of their own and began to take notes - in a separate journal, marginal notes in the book (gasp!), or colorful notes on their Kindles.

A timetable. In summer 2014, when Nella moved to Texas, we began the club. We discuss books when ready, which seems

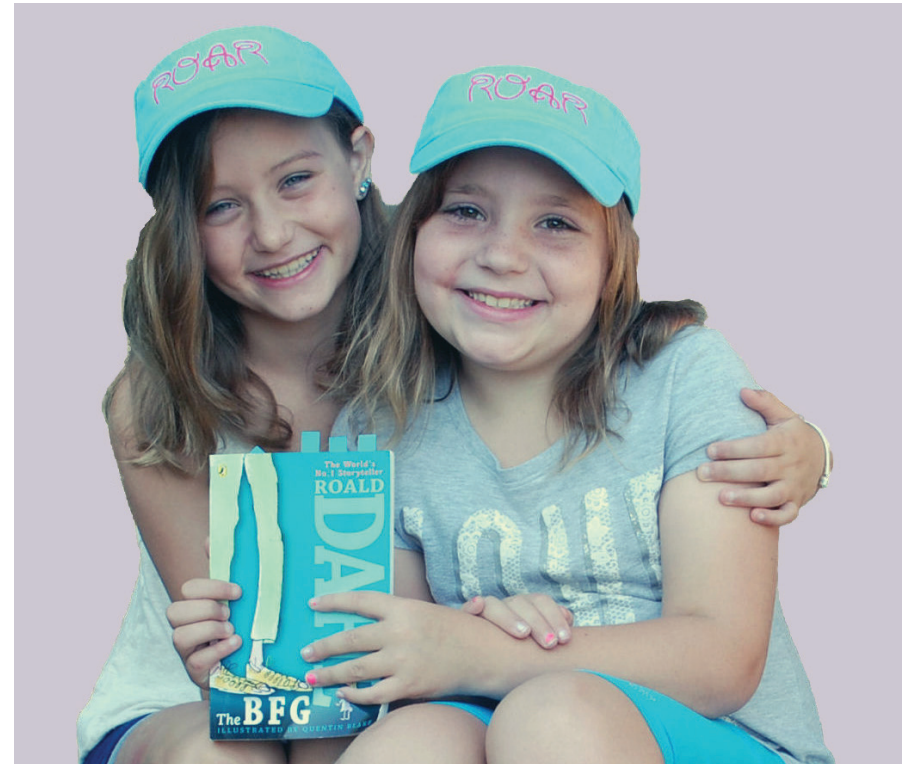

to be seasonal. They find time for pleasure reading and take a book wherever they go, read before bedtime, and, of course, bring one over when they come to Gramma's house.

Whether a hardcover, paperback, or e-book. We all agree that the best part is that we are reading together. ROAR! \&.

Edwina Walker Amorosa is a life-long reader who now finds joy in providing every opportunity to pass on the pleasure of reading to her eight grandchildren. Professionally, she is a book indexer; formerly, an elementary school library director, journal editor/reviewer, and high school and university English and reading teacher/instructor.

Got a great, lighthearted essay? A funny story about children and libraries? Books and babies? Pets and picture books? A not-so-serious look at the world of children's librarianship? Send your Last Word to Sharon Verbeten at CALeditor@yahoo.com. 